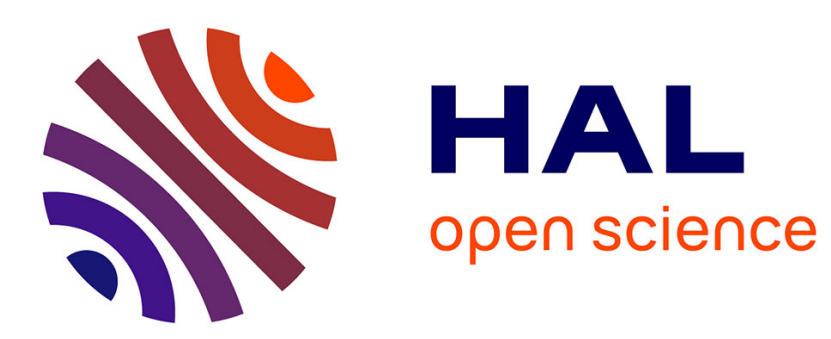

\title{
Assessing the Effect of Microfinance on Vulnerability and Poverty among Low Income Households
}

\author{
Ranjula Bali Swain, Maria Floro
}

\section{To cite this version:}

Ranjula Bali Swain, Maria Floro. Assessing the Effect of Microfinance on Vulnerability and Poverty among Low Income Households. The Journal of Development Studies, 2012, pp.1. 10.1080/00220388.2011.615917 . hal-00814934

\section{HAL Id: hal-00814934 https://hal.science/hal-00814934}

Submitted on 18 Apr 2013

HAL is a multi-disciplinary open access archive for the deposit and dissemination of scientific research documents, whether they are published or not. The documents may come from teaching and research institutions in France or abroad, or from public or private research centers.
L'archive ouverte pluridisciplinaire HAL, est destinée au dépôt et à la diffusion de documents scientifiques de niveau recherche, publiés ou non, émanant des établissements d'enseignement et de recherche français ou étrangers, des laboratoires publics ou privés. 


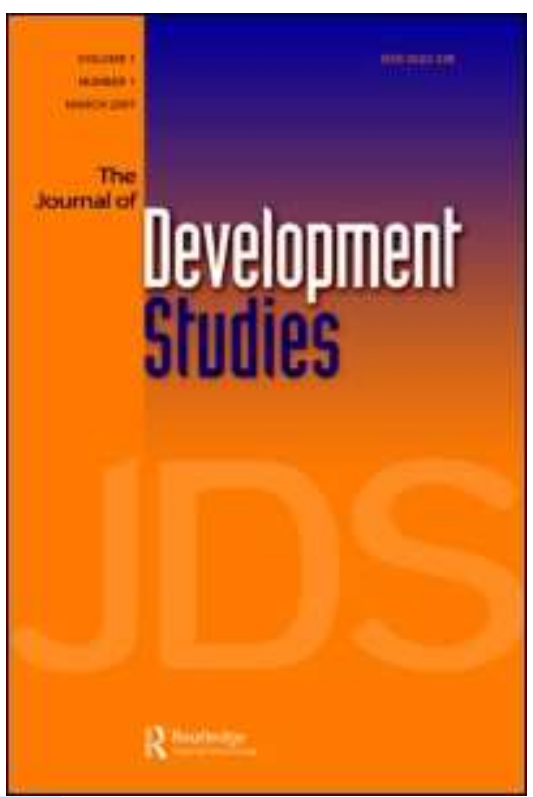

\section{Assessing the Effect of Microfinance on Vulnerability and Poverty among Low Income Households}

\begin{tabular}{|r|l|}
\hline Journal: & Journal of Development Studies \\
\hline Manuscript ID: & FJDS-2009-Dec-0010.R2 \\
\hline Manuscript Type: & Original Manuscripts \\
\hline Keywords: & $\begin{array}{l}\text { Poverty < Social Issues, Vulnerability < Social Issues, Economics < } \\
\text { Economics, Asia < Geographical Area }\end{array}$ \\
\hline \multicolumn{2}{|c}{} \\
\hline
\end{tabular}

\section{SCHOLARONE \\ Manuscripts}


Revised Manuscript: FJDS-2009-Dec-0010.R1

\title{
Assessing the Effect of Microfinance on Vulnerability and Poverty among Low Income Households
}

\begin{abstract}
We empirically investigate whether participation in Indian Self Help Group microfinance program (SHG) has helped reduced poverty and household vulnerability using cross-sectional SHG rural household survey data. The potential selection bias is eliminated by propensity score matching to estimate the average treatment on treated effect using nearest neighbour matching and local linear regression algorithm. We find that vulnerability in SHG members is not significantly higher than the non-SHG members, even though the SHG members have a high incidence of poverty. However, vulnerability declines significantly for those that have been SHG members for more than one year. These results are found to be robust using sensitivity analysis and Rosenbaum bounds method.
\end{abstract}

JEL Classifications: D14, G21, I32.

Keywords: Microfinance, Vulnerability, Poverty, Self Help Groups. 


\section{Introduction}

An extensive literature has examined the impact of microfinance in alleviating poverty (Morduch, 1999). While several studies have shown positive impact in reducing poverty, a number have challenged this view expounding that the results are more mixed (Morduch, 1999; Amin et al., 1999; Puhazhendi and Badatya, 2002; de Aghion and Morduch, 2006; Karlan, 2007). ${ }^{1}$ Exploring beyond poverty, this paper investigates if microfinance reduces household vulnerability. In other words, do microfinance programs reduce the household exposure to future shocks and improve their ability to cope with them? Answering this question is crucial since the goal of poverty alleviation is not just about improving economic welfare via increased incomes and consumption. It is also about devising means for preventing households from falling into poverty and enabling them to meet their survival needs including food security, to make productive investments and to avoid selling their limited resources in times of income or expenditure shocks. Static poverty measures are helpful in assessing the current poverty status of households but tend to ignore poverty dynamics over time. ${ }^{2}$ Thus even though average household incomes do not fall into poverty levels, their degree of vulnerability or the risk of being poor in the future, can still remain high. The cumulative impact of microfinance programs on the household's wellbeing may therefore not be captured by standard poverty measures alone. A limited literature on the impact of microfinance on vulnerability provides evidence that microfinance tends to strengthens crisis coping mechanisms, helps diversify income-earning sources, and enables asset creation. In fact, a few studies suggest that it has a more significant impact in reducing vulnerability than income-poverty (Hashemi et al., 1996; Morduch, 1999). 
Our objectives in this paper are two-fold. First, we estimate two important dimensions of well-being namely, poverty and ex-ante vulnerability of households in SHG and non-SHG groups using 2003 rural household survey data. Secondly, we empirically investigate whether microfinance programs like Self Help Group program (SHG) lead to a reduction in vulnerability or not. Vulnerability in our study is defined as a forward-looking, ex-ante measure of the household's ability to cope with future shocks and proneness to food insecurity that can undermine the household's survival and the development of its members' capabilities.

The empirical analysis is based on a 2003 household survey data collected on one of the largest microfinance programs in the developing world, the National Bank for Agriculture and Rural Development (NABARD) self-help group (SHG) program in ten rural districts in India. We estimate several poverty measures as well as an ex-ante vulnerability measure using Chauduri, Jalan and Suryahadi (2002) methodology, which allows for household vulnerability estimation using cross-sectional data. We also take into account any variation in the effect of SHG participation on vulnerability due to difference in the economic environment and the design of the SHG bank linkage. We correct for potential selection bias in the household sample using propensity score matching to obtain the average treatment on treated effect (impact) on vulnerability. Finally we test the sensitivity of the results to unobservables.

Some researchers suggest that the poor are likely to be more vulnerable (Prowse, 2003; Cannon et al., 2003; Feldbrügge and von Braun, 2002). If this is the case, then the SHG members, with a higher proportion of poor households, are likely to be more vulnerable. Controlling for selection bias, our results show that SHG member households are not more vulnerable than non-member households, even though a higher proportion of them are poor. 
Among the more mature SHG members however, we find a significant reduction in vulnerability compared to the non-SHG members. These results are found to be robust using the sensitivity analysis and Rosenbaum bounds method.

The paper is organized as follows. Section 2 discusses the notion of vulnerability and the conceptual framework used in the estimation of vulnerability. Section 3 explores the role of microfinance SHGs in reducing vulnerability. Section 4 provides an overview of the sample data used in our analysis and the methodologies used in addressing potential participation bias, in estimating vulnerability, and in assessing the effect of SHG participation. Section 5 provides the results of the propensity score matching and the resulting poverty and vulnerability estimates for SHG and non-SHG members. The results of sensitivity analyses involving the use of affected treatment on treated (ATT) effect and Rosenbaum bounds methods to test the robustness of the propensity score matching estimates are provided in section 6. Concluding remarks are presented in the final section.

\section{Understanding Vulnerability}

It should be noted that vulnerability as a notional concept, has been viewed differently by researchers, thus leading to varied definitions and measures. Some see vulnerability as an aspect which can cause poverty or hinder people from escaping out of poverty (Prowse, 2003: 9). This view that poor people are generally more vulnerable is shared by Cannon et al. (2003) and Feldbrügge and von Braun (2002). Some have taken a different perspective of vulnerability whereby poverty is viewed as one element, which may contribute to an enhanced vulnerability (Cardona, 2004). Others such as Calvo (2008) treat vulnerability as a dimension of poverty itself and define it as a threat of suffering any form of poverty in the 
future. $^{3}$ In Calvo and Dercon's (2005) model, vulnerability is seen as a combination of poverty (failure to reach a minimum outcome) and risk (dispersion over states of the world) that translates into a threat of being poor in the next period. This notion of vulnerability builds upon the probability of outcomes failing to reach the minimal standard as well as on the uncertainty about how far households may fall below that threshold. This uncertainty is a source of distress and impinges directly on well-being. Chauduri, Jalan and Suryahadi (2002) in their study of Indonesian households, define vulnerability within the framework of poverty eradication as the ex-ante risk that a household will, if currently non-poor, fall below the poverty line, or if currently poor, will remain in poverty. (p. 4). On the other hand, Ligon and Schechter (2003) take a utilitarian approach in defining vulnerability, arguing that it depends not only on the mean of household consumption but also on variation in consumption in the context of a risky environment. The risk faced by the household is decomposed into aggregate and idiosyncratic risk. A growing number of empirical studies have proposed varied measures and proxy indicators of vulnerability as well (Zimmerman and Carter, 2003; Calvo and Dercon, 2005; Glewwe and Hall, 1999; Ligon and Schechter, 2003; Carter and Barrett, 2006; Morduch, 2005). Some make use of household panel data, where available, to analyze the extent of consumption fluctuations over time as households experience income fluctuations (Morduch, 2005; Kamanou and Morduch, 2005). Other studies examine the impact of various forms of shocks on households' consumption (Ligon and Schechter, 2003; Carter et al., 2007), or other aspects of household well-being, for instance, health (Dercon and Hoddinott, 2005). While there are efforts to address data issues, empirical analyses of vulnerability remain severely constrained by the paucity of panel data in many developing countries and by limited information on the idiosyncratic and covariate shocks experienced by households (Günther and Harttgen, 2009:1222-23). Chauduri et al. (2002) propose a method for estimating vulnerability that can be applied to cross-sectional household surveys such as the 2003 Indian 
rural household survey, thus avoiding the data problems mentioned. It has been adopted in a number of vulnerability studies including Zhang and Wan (2006), Günther and Harttgen (2009) and Imai, Wang and Kang (2010). ${ }^{4} \quad$ A discussion of this vulnerability estimation method is presented in section 4 .

\section{Microfinance Self-help Groups and Household Vulnerability}

Very few studies have explored the effect of microfinance in terms of reducing vulnerability. Evidence on Bangladeshi microfinance institutions conclude that microfinance access has led to consumption smoothing or a reduction in the variance in consumption by member households across time periods (Khandker, 1998; Morduch, 1999; Zaman 2000). Puhazhendi and Badatya (2002) study finds that microfinance provides loans for both production and consumption purposes, thereby allowing consumption smoothing and enabling households to mitigate the effects of negative shocks.

Building on these studies, we argue in this paper that microfinance SHG participation can help member households in the face of liquidity constraints and multitude of risks, thereby reducing their vulnerability. For instance, SHG program provide loans to those members who face liquidity constraints in meeting investment needs as well as unexpected consumption expenses. These production and consumption loans help ease the members' productivity and earnings and help their households coping with contingencies and idiosyncratic shocks. The training of members provided by the SHG program also can enhance their entrepreneurship skills as well as their ability to perceive and process new information, evaluate and adjust to changes, thus increasing both their productivity and self-confidence. 
In addition, SHGs can promote or strengthen social networks that provide mutual support by facilitating the pooling of savings, regular meetings, etc that help empower their members, especially women. Group meetings are often used to discuss communal issues leading to improved ability of member households to manage risk and deal with shocks These nonpecuniary effect of SHGs can reduce the vulnerability of the members and by association, that of their households in ways that may not be adequately captured by change in household earnings alone.

While SHGs may help rural households deal with vulnerability to idiosyncratic shocks the protection afforded by them in dealing with covariate shocks such as epidemics, flooding or declining crop prices is likely to be weak (Zimmerman and Carter, 2003; Morduch, 2004; Dercon, 2005). ${ }^{5}$ An enabling economic environment and the presence of services and infrastructural support such as health centers and flood control systems that reduce exposure to these aggregate shocks can help enhance the effectiveness of SHGs in reducing household vulnerability,

\section{Data and Methodology}

\subsection{Data Description}

The NABARD SHG-bank linkage program in India is one of the largest and fastest-growing microfinance programs in the developing world. Initiated in 1996, the SHG program has grown to finance 687,000 SHGs in $2006-07$ as compared to 198,000 SHGs in 2001-02. According to NABARD (2006), about 44,000 branches of 547 banks and 4,896 NGOs participate in the SHG bank linkage program. These microfinance SHGs typically include ten to twenty (primarily female) members in the village. In the initial months, the group members 
save and lend amongst themselves to build group financial discipline. Once the group demonstrates stability for six months, it receives loans of up to four times the amount it has saved. The bank then disburses the loan and the group decides how to manage the loan. As savings increase through the group's life, the group accesses a larger amount of loans. The SHGs are linked to banks in several ways: SHGs that are formed and financed by banks (model 1), those formed by NGOs but directly financed by banks (model 2), and those that are formed by the NGOs and financed by the banks through the NGOs (model 3).

The data used for the empirical analyses in this paper was collected in 2003 as part of a larger study that investigates the NABARD SHG-bank linkage program. ${ }^{6}$ The sample survey was conducted in two representative districts of the following five states: Orissa, Andhra Pradesh, Tamil Nadu, Uttar Pradesh, and Maharashtra. ${ }^{7}$ NABARD's choice to expand the SHG program occurs at the district level without any specific policy to target certain villages (Bali Swain and Varghese, 2009). Thus, within the states, the study selected to sample at the district level, which is the basic administrative unit, avoiding those districts with over and under exposure of SHGs. The sampling strategy involved random selection of SHG memberhouseholds in each district The control group (non-SHGs) was chosen to reflect a comparable socio-economic group as the SHG respondents. These households were selected from villages that were similar to the SHG villages in terms of the level of economic development, sociocultural factors and infrastructural facilities, but did not have a SHG program. After refining the data further and dropping those with missing values, we are left with a sample of 840 households.

Table 1 shows characteristics of SHG and non-SHG members and their households. In general, SHG members are younger, have higher level of education, and have less non-land 
wealth compared to non-SHG respondents. They also have higher food consumption per capita per month and bigger landholding size compared to non-SHG households, although there is large variation in land quality. SHG households live in villages that are closer to public transport and primary health care centres but further away from banks, compared to non-SHG households. Using a subjective indicator based on the survey response as to whether or not their household experienced severe shortage of food and/or cash in the past three years, we find that $39 \%$ of the SHG households have experienced economic difficulties, compared to $27 \%$ of non-SHG households. The t-test results confirm the significant difference between the SHG members and non-members in terms of size of landholdings and their access to market infrastructure and services, as well as incidence of food and/or cash shortage in the past.

$<$ Table 1 about here $>$

\subsection{Propensity Score Matching Method}

The decision to participate in SHGs depends on the same attributes that determine the vulnerability of the household. Self-selection bias could arise from the potentially unobservable traits of the SHG members. For instance, higher entrepreneurship, ability to recognize opportunity, and other critical aspects make the households more likely to participate in the SHG program. However, the same characteristics could also affect their vulnerability. A number of studies on microfinance have addressed the problem of selection, reverse causality and other biases using different approaches. 
To correct for selection bias created by program selection, we use the propensity score matching (PSM) method. This technique allows us to identify the program impact when a random experiment is not implemented, as long as there is counterfactual or control group. In contrast to other regression methods, the PSM does not depend on linearity and has a weaker assumption on the error term. The matching relies on the assumption of conditional independence of potential outcomes and treatment given observables. The data collection method meets the three conditions outlined in Heckman et al. (1997), thus allowing the use of the PSM method. First, the survey questionnaire is the same for participants and nonparticipants and therefore yields the same outcome measures. Second, both groups come from the same local environment or markets. Third, a rich set of observables for both outcome and participation variables are available for the performance of the PSM method.

As with any impact evaluation, the main problem with identifying SHG impact is that the outcome indicator for SHG member households with and without program is not observed because by definition, all the participants are SHG members in period 1. Since we only have information on the households once they participate in the program, there is need to identify a control group that allows us to infer what would have happened with the SHG participant household if the SHG program would not have been in place. The PSM uses the "Propensity Score" or the conditional probability of participation to identify a counterfactual group of non participants, given conditional independence.

The probability $(\mathrm{P}(\mathrm{X}))$ of being selected is first determined by a logit equation and then this probability (the propensity score) is used to match the households. $\mathrm{Y}_{1}$ is the outcome indicator for the SHG program participants $(\mathrm{T}=1)$, and $\mathrm{Y}_{0}$ is the outcome indicator for the SHG members $(\mathrm{T}=0)$, then equation (1) denotes the mean impact: 


$$
\Delta=E\left[Y_{1} \mid T=1, P(X)\right]-E\left[Y_{0} \mid T=0, P(X)\right]
$$

where the propensity score matching estimator is the mean difference in the outcomes over common support, weighted by the propensity score distribution of participants.

The literature proposes several propensity score matching methods to identify a comparison group. ${ }^{8}$ Since the probability of two households being exactly matched is close to zero, distance measures are used to match households. Following Smith and Todd (2005), we first choose the neighbor to neighbor (NN) algorithm (with one person matching). This algorithm is the most straightforward and matches partners according to their propensity score. We further estimate the local linear regression (LLR) method (for bandwidths 1). ${ }^{9}$ The LLR method uses the weighted average of nearly all individuals in the control group to construct the counterfactual outcome. Bootstrapped standard errors for the LLR procedures are used (Abadie and Imbens, 2007; Heckman et al., 1997).

\subsection{Estimating Poverty and Vulnerability}

We examine the poverty profile of the SHG and non-SHG households using standard measures of poverty such as the headcount ratio, poverty gap ratio and the squared poverty gap or Foster-Greer-Thorbecke (FGT). The head count ratio measures the proportion of population under the poverty line. The poverty gap ratio measures the depth of poverty and is the total amount that is needed to raise the poor from their present incomes to the poverty line as a proportion of the poverty line and averaged over the total population. The squared poverty gap or FGT index takes inequality among the poor into account and captures the severity of poverty. 
The poverty line used in our study is based on the official (consumption-based poverty) line for India, which assumes the minimum subsistence requirement of 2400 calories per capita per day for rural areas. The official poverty line estimate is derived from the household consumer expenditure data collected by National Sample Survey Organisation (NSSO) of the Ministry of Statistics and Programme Implementation, every fifth year. Since the poverty line estimate is drawn from the $61^{\text {st }}$ round of the NSS which covers period July 2004 to June $2005^{10}$, we adjust the official poverty line using the 2003 Consumer Price Index for agricultural workers in rural areas to correspond with the survey period. Hence our estimated 2003 poverty line is Rs 356.3 per capita per month.

Next, we estimate the household's vulnerability using the Chauduri, Jayan and Suryahadi (2002) approach that allows the estimation of expected consumption and its variance with cross-section data. The Chauduri et al. approach is widely used in several studies on vulnerability (Jha and Dang, 2009; Zhang and Wan, 2006; Imai et al., 2010) and is considered to be one of the best estimators (Ligon and Schechter, 2004). ${ }^{11}$ It is based on the notion of vulnerability as the probability of being poor and implies accounting for the expected (mean) consumption, as well as the volatility (variance) of its future consumption stream. The stochastic process generating the consumption of the household is dependent on the household characteristics and the error term (with mean zero). It captures the idiosyncratic shocks to consumption that are identically and independently distributed over time for each household. Hence, any unobservable sources of persistent or serially correlated shocks or unobserved household specific effects over time on household consumption are ruled out. It also assumes economic stability thereby ruling out the possibility of aggregate shocks. Thus the future consumption shocks are assumed to be idiosyncratic in nature. This does not mean however, that they are identically distributed across households. Furthermore, we assume that 
the variance of the idiosyncratic factors (shocks) depend upon observable household characteristics.

Following Chauduri et al (2002) approach, we assume that the vulnerability level of a household $h$ at time $t$ is defined as the probability that the household finds itself to be consumption poor in period $t+1$. The household's consumption level depends on several factors such as wealth, current income, expectation of future income (i.e. lifetime prospects), the uncertainty it faces regarding its future income and its ability to smooth consumption in the face of various income shocks. Each of these, in turn, depend on a number of household characteristics, both observed and unobserved, the socio-economic environment in which the household is situated, and the shocks that contribute to differential welfare outcomes for households that are otherwise observationally equivalent. Hence, the household's vulnerability level in terms of its future food consumption can be expressed as a reduced form for consumption determined by a set of variables $\mathrm{X}_{\mathrm{ht}}$ :

$$
\ln c_{\mathrm{ht}}=\beta_{0}+\mathrm{X}_{\mathrm{ht}} \beta_{1}+\mu_{\mathrm{ht}}
$$

where $\ln c_{\mathrm{ht}}$ represents $\log$ of consumption per capita on adult equivalence scale, $\mathrm{X}_{\mathrm{ht}}$ represents selected household and community level characteristics, and $\mu_{\mathrm{ht}}$ is the unexplained part of household consumption. Since the impact of shocks on household consumption is correlated with the observed characteristics, the variance of the unexplained part of consumption $\mu_{\mathrm{ht}}$ is:

$$
\sigma_{\mathrm{h}}^{2}=\Phi_{0+} \Phi_{1} \mathrm{X}_{\mathrm{ht}+} \omega_{\mathrm{ht}}
$$


which implies that the variance of the error term is not equal across households and depends upon $\mathrm{X}_{\mathrm{ht}}$. The latter include respondent's educational attainment, household composition, number of workers in the household, and household wealth proxy. We also take into account the environment characteristics such as access to paved roads, markets, health care services, and public transportation. Given data limitations, we cannot identify the particular stochastic process generating $\beta$. The expected mean and variance per capita household food consumption are estimated using a simple functional form by Amemiya's (1977) three-step feasible generalized least squares (FGLS). ${ }^{12}$ Using the obtained $\beta_{1}$ and $\Phi_{1}$ estimates, we estimate the expected $\log$ consumption and the variance of $\log$ consumption for each household. These serve as vulnerability estimates.

To facilitate comparison of the vulnerability distribution among SHG and non-SHG households, we estimate additional measures using different thresholds in order to examine the sensitivity of our results to the choice of vulnerability threshold. The relative vulnerability threshold uses the observed poverty rate in the population, which is approximately equal to the mean vulnerability level within a group in the absence of aggregate shocks (Chauduri et al., 2002). Thus, vulnerability levels above the observed poverty rate threshold imply that the household's risk of poverty is greater than the average risk in the population, thus making it more vulnerable. We use the official rural poverty rate by the Planning Commission of India as the first vulnerability threshold. ${ }^{13}$

Another vulnerability threshold is 0.50 . Households with vulnerability levels between observed poverty rates and 0.50 threshold are termed relatively vulnerable whereas those above 0.50 are considered highly vulnerable. Finally, the vulnerability to poverty ratio, measures the fraction of the vulnerable population to the fraction that is poor. The higher the 
vulnerability to poverty ratio the more spread is the distribution of vulnerability. Whereas a lower vulnerability to poverty ratio implies greater concentration of vulnerability amongst a few households. Admittedly, there is some arbitrariness involved in the selection of the vulnerability thresholds so a comparison of the vulnerability estimates using additional vulnerability thresholds shows the sensitivity of the results to the choice of vulnerability threshold.

\section{Empirical Analysis}

This section presents the logistic and the propensity score results of matching. This is followed by a discussion on the poverty and the estimated vulnerability measures of SHG and non-SHG member households. We then present the estimated average treatment on treated (ATT) effect of SHG participation using different matching algorithms that takes potential selection bias into account. The robustness of our results are then checked for sensitivity to unobservables.

\subsection{Propensity Score Matching}

We correct for potential selection bias using PSM method by first estimating a parsimonious logistic equation in order to determine the probability of participating in the SHG program. ${ }^{14}$ The variables that likely affect both the participation in SHG and the outcome variable (real food expenditure per capita per month) were chosen and these include age, age squared, sex, education dummies, lack of cash or food 3 years ago, owned land 3 years ago, distance from bank, health care centre, marketplace, and paved road. ${ }^{15}$ We obtained very similar results with both neighbour to neighbour algorithm (with one person matching) and log linear regression 
method (for bandwidths 1). Appendix 1 shows the propensity score estimation using logistic regression. It indicates that landholding size in 2000, incidence of money or food shortage (in 2000), and distance from the bank and market affect the probability of participating in the SHG. Other variables such as age, gender and education level of the respondent do not significantly explain SHG participation.

Using the derived propensity scores, we drop those SHG respondents with probabilities that cannot be matched to the propensity scores of the control group, leaving us with a sample of 742 households comprised of 691 SHG and 51 non-SHG (control group) households. Of the 691 SHG households, 532 have been members for more than one year (referred to as mature SHG members) and 159 belong to newly-formed groups. Only the households on the common support are retained to assure comparability. Prior to matching, the estimated mean propensity scores (standard error) for SHG members and non-SHG member were $0.94(0.05)$ and 0.89 (0.06) respectively. Appendix 2 provides the histograms of the estimated propensity scores for the two groups. After the matching, there was a negligible difference in the mean propensity scores of the two groups $(0.93(0.04)$ for SHG members and $0.89(0.06)$ for nonSHG members).

\subsection{Poverty and Vulnerability Profile for SHG and non SHG members}

We construct a poverty profile of the SHGs (treatment group) and the non-SHG member (control group) in 2003 using standard measures such as the headcount index, poverty gap index and the squared poverty gap index. ${ }^{16}$ Table 2 presents the poverty profile of the SHG member and non-member households using standard poverty measures. ${ }^{17}$ Our results show that a higher proportion of the SHG members are poor (72.5 per cent as compared to 60.8 per 
cent for the non-members) although the depth of poverty is about the same between SHG and non-SHG households. Their aggregate poverty gap per household is Rs.123 compared to Rs 118 among non-SHGs. The FGT index shows that there is slightly greater inequality among the non-SHG poor (0.24) compared to the SHG poor $(0.22)$.

\section{$<$ Table 2 about here $>$}

Following Chauduri et al. (2002) the vulnerability estimates are obtained from the FGLS estimates and are presented in Appendix 3. ${ }^{18}$ The mean vulnerability level within the SHG member-household group is much lower (0.45) and statistically significant as compared to the SHG non-members (0.62). This implies that participation in SHGs may reduce the vulnerability of the households.

We also examine the mean vulnerability and sensitivity of the vulnerability estimate to the choice of a threshold. We use three different vulnerability thresholds in our study namely: a) the observed poverty rate; b) the vulnerability threshold of lying above the observed poverty rate but with a 50 percent probability of falling into poverty at least once in the next year; and c) the highly vulnerable lying above the vulnerability threshold of 0.5 for a one year time period. We also report the ratio of the proportion of households that are vulnerable to the proportion that are poor. This is an indication of how dispersed vulnerability is in the population.

The fraction of the population which is vulnerable with respect to these three thresholds is given in Table 2. Even though a higher proportion of SHG members are poor, they are relatively less vulnerable $(0.55)$ as compared to the non-SHG (0.72). Not only are the non- 
SHG members more vulnerable, a larger proportion of them (0.69) are highly vulnerable. The non-members also have a higher vulnerability to poverty ratio (1.18) with a greater dispersion in incidence of vulnerability. We further examine the subset of SHG participants that have been members for more than one year. Their poverty and vulnerability profile is very similar to that of the SHG members (see Appendix 4).

The above results indicate that there is a large proportion of currently poor SHG members, whose vulnerability level is low enough for them to be classified as non-vulnerable. This reflects the stochastic nature of the relationship between poverty and vulnerability. While poverty and vulnerability are related concepts, the characteristics of those observed to be poor at any given point in time may differ from the characteristics of those who are vulnerable to poverty.

\subsection{Impact on Vulnerability Controlling for Selection Bias}

We now estimate the impact on our outcome variables taking the selection bias from participation into account. Heckman et al. (1997) suggest that in small samples the choice of the matching algorithm can be important, due to trade-offs between bias and variances. Thus, Caliendo and Kopeinig (2008) suggest that multiple algorithms should be tried and if they give similar results, the choice may be unimportant.

Using two different algorithms for propensity score matching to identify the comparison group, we estimate the ATT. Nearest Neighbour matching algorithm (NN) is the more intuitive of the two as it matches each treated observation to a control observation with the closest propensity score. We also employ the local linear regression (LLR) algorithm one to 
one person matching (bandwidth 1), which is a generalised version of kernel matching that allows faster convergence at the boundary points. ${ }^{19}$ Table 3 presents the Average Treatment on Treated estimates (ATT) of SHG participation impact on vulnerability and average food expenditure per capita per month.

\section{$<$ Table 3 about here $>$}

The magnitude of the ATT estimates in Table 3, measures the impact of SHG participation on the outcome variables (vulnerability and food expenditure), controlling for the selection bias. Table 3, column 1 shows that the ATT point estimates (both NN and LLR) are positive but statistically insignificant for vulnerability. This indicates that after accounting for selection bias the SHG members are neither more nor less vulnerable as compared to the non members. ${ }^{20}$ However, the SHG participants that have been members for more than a year, show a significantly lower level of vulnerability. This suggests that the impact of microfinance on vulnerability takes longer time. . By design, the SHG bank linkage program provides credit to those groups that have demonstrated financial maturity and stability during the first six months of their existence. Thus, the more mature (older than one year) groups are credit linked and have the possibility to use microfinance for reducing vulnerability whereas the newly formed SHGs are not. SHG participation on the other hand does lead to an increase in its average food expenditure per capita per month compared to that of non-SHGs using the LLR algorithm method (Table 3, column 2). A likely reason for this might be due to the provisioning of SHG loans that may be used for any purpose (including consumption) and thus helps the households cope with economic shocks. Taking the subset of the more mature SHGs however, the results do not show any significant increase in average food expenditure. Our results show that even though the current poverty status of SHG member households has 
a very high proportion of poor with a higher aggregate poverty gap, their propensity to become poor in the next period (vulnerability) is not higher. The more mature SHG participants, however, have significantly lower level of vulnerability.

\section{Sensitivity Analysis - Robustness of Results}

The propensity score matching hinges on the conditional independence or unconfoundedness assumption (CIA) and unobserved variables that affect the participation and the outcome variable simultaneously that may lead to a hidden bias due to which the matching estimators may not be robust. It is not possible to directly reject the unconfoundedness assumption however. Heckman and Hotz (1989) and Rosenbaum (1987) have developed indirect ways of assessing this assumption. These methods rely on estimating a causal effect that is known to be equal to zero. If the test suggests that this causal effect differs from zero, the unconfoundedness assumption is considered less plausible (Imbens, 2004).

Building on Rosenbaum and Rubin (1983) and Rosenbaum (1987), Ichino, Mealli and Nannicini (2008) propose a sensitivity analysis that we adopt in this paper. They suggest that if the CIA is not satisfied given observables but is satisfied if one could observe an additional binary variable (confounder), then this potential confounder could be simulated in the data and used as an additional covariate in combination with the preferred matching estimator. The comparison of the estimates obtained with and without matching on the simulated confounder shows to what extent the baseline results are robust to specific sources of failure of the CIA, since the distribution of the simulated variable can be constructed to capture different hypotheses on the nature of potential confounding factors. 
To check the robustness of our ATT estimates, we use two covariates to simulate the confounder namely: young (respondents under the age of 26 years) and illiterate (with no education). These covariates are selected in order to capture the effect of 'unobservables' like ability, entrepreneurial skills, experience and risk aversion etc., which may have an impact on the member participation in the SHG program and on the vulnerability of the household. If the ATT estimate change dramatically with respect to the confounders, then it would imply that our results are not robust. We employ the Kernel matching algorithm with betweenimputation standard error, in order to use only the variability of the simulated ATT across iterations. Since our outcome variable is continuous, the confounder is simulated on the basis of the binary transformation of the outcome along the $25^{\text {th }}$ centile. The results of these two confounders $^{21}$ are presented in Table 4. For both the 'young' and 'no education' confounders the simulated ATT estimates are very close to the baseline estimate. The outcome and selection effect on vulnerability is positive but not very large. The results indicate a robustness of the matching estimates.

\section{$<$ Table 4 about here $>$}

We further test the robustness of our results using Rosenbaum's (2002) bounding approach and find our results to be robust (see Appendix 5, with discussion).

\section{Concluding Remarks}

This paper explores an important dimension of household welfare that conventional measures of poverty do not address, namely vulnerability. We examine the likely effect of Self-Help microfinance groups (SHG) on the vulnerability of participating member households using an 
Indian household sample survey data from 2003. We argue that a household's ability to mitigate risk and cope with shocks is enhanced through SHG participation by increasing household earnings through provision of microfinance and training, aiding the household in the face of shocks by providing consumption loans, and enhancing their resilience by strengthening social support and improving women's empowerment.

We use propensity score matching to extricate the potential selection bias that may arise due to unobservable attributes. Additionally, we empirically examine the current poverty status of households in SHG and non-SHG groups using several poverty measures and then make inferences about whether or not these households are currently vulnerable to future poverty using the Chauduri et al. approach. After matching the treated and comparison groups on the basis of their propensity scores, we estimate the average treatment on treated effect using nearest neighbour matching algorithm and local linear regression. The robustness is checked with help of sensitivity analysis and Rosenbaum bounds. Our main empirical results show that after we account for the selection bias, even though SHG-member households are found to be poorer than the non-SHG member (control group) households, they are not more vulnerable. Vulnerability is significantly lower for the more mature households as compared to the nonSHG members These results are found to be robust using the sensitivity analysis and Rosenbaum bounds method.

The SHG bank linkage program is a joint liability microfinance program where the loan may be used for any purpose, be it production or consumption. Microfinance in this case provides an additional resource for consumption smoothing thus reducing the variability in food consumption levels and hence vulnerability. Finally, microfinance SHG can strengthen 
mutual support networks that help reduce vulnerability of members and that of their households in ways that may not be adequately captured by the change in household earnings. 


\section{References}

Abadie, A. and Imbens, G. (2007) Bias Corrected Matching Estimators for Average Treatment Effects, Working Paper, Department of Economics, Harvard University.

Amin, S., Rai, A.S. and Topa, G. (1999) Does Microcredit Reach the Poor and Vulnerable? Evidence from northern Bangladesh.Working paper 28, Centre for International Development, Harvard University.

Amemiya, T. (1997) The Maximum Likelihood Estimator and the Non-linear Three Stage Least Squares Estimator in the General Nonlinear Simultaneous Equation Model, Econometrica, 45, pp. 955-968.

Bali Swain, R. and Varghese, A. (2009) Does Self Help Group Participation Lead to Asset Creation?, World Development, 37(10), 1674-1682, 2009.

Becker, S. and Ichino, A. (2002) Estimation of Average Treatment Effects Based on Propensity Score. The Stata Journal 2: 358-377.

Caliendo, M., and Kopeinig, S. (2008) Some Practical Guidance for the Implementation of Propensity Score Matching. Journal of Economic Surveys, 22, pp.31-72.

Calvo, C. (2008) Vulnerability to Multidimensional Poverty: Peru, 1998-2002. World Development, 36 (6), pp. 1011- 1020.

Calvo, C. and Dercon, S. (2005) Measuring Individual Vulnerability, Department of Economics Working Paper Series, 229, (Oxford: Oxford University).

Cannon, T. T, and Rowell, J. (2003) Social Vulnerability, Sustainable Livelihoods and Disasters. Report to DFID. Conflict and Humanitarian Assistance Department (CHAD) and Sustainable Livelihoods Office, London.

Cardona, O.D. (2004) The Need for Rethinking the Concepts of Vulnerability and Risk from a Holistic Perspective: a Necessary Review and Criticism for Effective Risk Management, in: Bankoff, G., Frerks, G., and D. Hilhorst (ed) Mapping Vulnerability: Disasters, Development and People (London: Earthscan publications), pp. 37-51.

Carter, M., and Barrett, C. (2006) The economics of poverty traps and persistent poverty: An asset-based approach. The Journal of Development Studies, 42 (2), pp. 178-199.

Carter, M., Little, P., Mogues, T., and Negatu, W. (2007) Poverty Traps and the Long term consequences of Natural Disasters in Ethiopia and Honduras, World Development, 35(5), pp. 835-856.

Carter, M. and Ikegami, M. (2007) Looking Forward: Theory-based measures of Chronic Poverty and Vulnerability, CPRS Working Paper No. 94, University of Wisconsin, Madison. 
Chauduri, S. Jalan, J. and Suryahadi, A. (2002) Assessing Household Vulnerability to Poverty from Cross Sectional Data: A Methodology and Estimates from Indonesia, Discussion paper 0102-52,Department of Economics, Columbia University.

De Aghion, B.A. and Morduch, J. (2006) The Economics of Microfinance,(Cambridge, Massachusetts: MIT Press).

Dercon, S. and Krishnan, P. (2000) Vulnerability, seasonality and poverty in Ethiopia. Journal of Development Studies, 36(6), pp. 25-53.

Dercon, S. (2005) Vulnerability: a micro perspective, Mimeo, (Oxford: Oxford University).

Dercon, S. and Hoddinott, J. (2005) Health, Shocks and Poverty Persistence in: Stefan Dercon (ed), Insurance Against Poverty, (Oxford: Oxford University Press), pp. 124-136.

Feldbrügge, T. and von Braun, J. (2002) Is the World Becoming A More Risky Place? Trends in Disasters and Vulnerability to Them. Discussion Papers on Development Policy No.46.Center for Development Research, Bonn.

Glewwe, P. and Hall, G. (1998) Are some groups more vulnerable to macroeconomic shocks? Hypothesis tests based on panel data from Peru. Journal of Development Economic, 56(1), pp. 181-206.

Günther, I. and Harttgen, K. (2009) Estimating Households Vulnerability to Idiosyncratic and Covariate Shocks: A Novel Method Applied in Madagascar. World Development, 37(7), pp. 1222-1234.

Hashemi, S.M., Schuler, S.R., Riley, A.P. (1996) Rural Credit Programs and Women's Empowerment in Bangladesh. World Development, 24(4), pp. 635-653.

Heckman, J. and Hotz, J. (1989) Alternative Methods for Evaluating the Impact of Training Programs (with discussion). Journal of the American Statistical Association, 84(804), pp. 862-874.

Heckman, J., Ichimura, H., and Todd, P. (1997) Matching as an Econometric Evaluation Estimator: Evidence from Evaluating a Job Training Programme. Review of Economic Studies, 64, pp. 605-654. Heitzmann, K., Canagarajah, R.S., P.B. Siegel (2002) Guidelines for Assessing the Sources of Risk and Vulnerability. Social Protection Discussion Paper Series. Social Protection Unit, The World Bank. Washington.

Ichino, A., Mealli, F. and Nannicini, T. (2007) From Temporary Help Jobs to Permanent Employment: What Can We Learn from Matching Estimators and their Sensitivity? Journal of Applied Econometrics, 23(3), pp. 305-327.

Imai, K.S., Wang, X., and Kang, W. (2010) Poverty and Vulnerability in Rural China: Effects of Taxation, Journal of Chinese Economic and Business Studies, 8(4), pp. 399-425.

Imbens, G. (2004) Non Parametric Estimation of Average Treatment Effects Under Exogeneity: A Review. The Review of Economics and Statistics, 86(1), pp. 4 -29.

Jha, R. and Dang, T. (2009) Vulnerability to Poverty in select Central Asian countries. The European Journal of Comparative Economics, 6(1), pp.17-50. 
Kamanou,G. and Morduch, J. (2005) Measuring Vunerability to Poverty in: Stefan Dercon (ed), Insurance Against Poverty, (Oxford: Oxford University Press), chapter 8.

Karlan, D. (2007) Impact Evaluation for Microfinance: Review of Methodological Issues November 2007, Poverty Reduction and Economic Management (PREM) Doing Impact Evaluation Discussion Paper 7, World Bank, Washington DC.

Khandker, S. R. (1998) Fighting Poverty with Microcredit: Experience in Bangladesh (New York: Oxford University Press, Inc).

Ligon, E. and Schechter, L. (2004) Evaluating Different Approaches to Estimating Vulnerability, Social Protection Discussion Paper 0201, World Bank, Washington D.C.

Ligon, E. and Schechter, L. (2003) Measuring Vulnerability. The Economic Journal, 113(486), pp. 95-102.

Ligon, E. and Schechter, L. (2002) Measuring Vulnerability: The director's cut. UN/WIDER Working Paper.

McCulloch, N. and B.Baulch (2000) Simulating the Impact of Policy upon Chronic and Transitory Poverty in Rural Pakistan. Journal of Development Studies, 36(6), pp. 100-130.

Morduch, J. (1999) The Microfinance Promise. Journal of Economic Literature, 37, pp. 15691614.

Morduch, J. (2004) Consumption Smoothing Across Space: Testing Theories of Risk-Sharing in the ICRISAT Study Region of South India, in: Stefan Dercon (ed), Insurance against Poverty (Oxford: Oxford University Press).

Morduch, J. (2005) Consumption Smoothing Across Space: Testing Theories of Risk-Sharing in the ICRISAT Study Region of South India in: Stefan Dercon (ed), Insurance Against Poverty, (Oxford: Oxford University Press) pp. 38-57.

National Bank of Agriculture and Rural Development (2006) Progress of SHG-Bank Linkage in India: 2005-06, Working Paper, NABARD, India.

National Bank of Agriculture and Rural Development (1992) Guidelines for the Pilot Project for linking banks with Self Help Groups, NB.DPD.FS. 4631/92-A/91-92, Circular No. DPD/104, India

Pitt, M. and Khandker, S.R. (1998) The Impact of Group-Based Credit Programs on Poor Households in Bangladesh: Does the Gender of Participants Matter? The Journal of Political Economy, 106, pp. 958-996.

Prowse, M. (2003) Towards a Clearer Understanding of 'Vulnerability' in Relation to Chronic Poverty. CPRC Working Paper No 24, University of Manchester.

Puhazhendi, V. and Badatya, K. C. (2002) SHG-Bank Linkage Programme for Rural Poor an Impact Assessment, Paper, National Bank for Agriculture and Rural Development- 
NABARD, Mumbai, India.

Rosenbaum, P. (1987) Sensitivity Analysis to Certain Permutation Inferences in Matched Observational Studies. Biometrika, 74(1), pp. 13-26.

Rosenbaum, P. (2002) Observational Studies. 2nd ed. (New York: Springer).

Rosenbaum, P. and Rubin, D. (1983) Assessing Sensitivity to an Unobserved Binary Covariate in an Observational Study with Binary Outcome. Journal of the Royal Statistical Society, Series B, 45, pp. 212-218.

Smith, J. and Todd, P. (2005) Does Matching Address Lalonde's Critique of Nonexperimental Estimators? Journal of Econometrics, 125, pp. 305-353.

Zhang, Y., and Wan, G. (2006) An Empirical Analysis of Household Vulnerability in Rural China. Journal of the Asia Pacific Economy, 11(2), pp.196-211.

Zimmerman, F. and Carter, M. (2003) Asset Smoothing, Consumption Smoothing and the Reproduction of Inequality Under Risk and Subsistence Constraints. Journal of Development Economics, 71, pp. 233-260. 


\section{TABLES}

Table 1

Selected Characteristics of Survey Respondents and their Households (standard deviation in parentheses)

\begin{tabular}{|c|c|c|c|}
\hline & All & SHG members & Non-SHG ${ }^{\dagger \dagger}$ \\
\hline $\mathrm{N}$ & 840 & 789 & 51 \\
\hline $\begin{array}{l}\text { Average Real food expenditure } \\
\text { per capita per month }\end{array}$ & $307(442)$ & $308(453)$ & $282(194)$ \\
\hline Average Age of Respondent & $35(8.41)$ & $35(8.44)$ & $36(8.08)$ \\
\hline \multicolumn{4}{|l|}{ Proportion with some (in \%) } \\
\hline Primary education & 18. & 18 & $24(0.43)$ \\
\hline Secondary education & 17 & 18 & 12 \\
\hline Post-Secondary education & 3 & 3 & 2 \\
\hline Average number of children & $1.5(1.27)$ & $1.5(1.27)$ & $1.4(1.25)$ \\
\hline Dependency ratio & $0.66(0.22)$ & $0.66(0.22)$ & $0.62(0.23)$ \\
\hline $\begin{array}{l}\text { Average number of workers in } \\
\text { the household }\end{array}$ & $2.48(1.24)$ & $2.46(1.23)$ & $2.70(1.40)$ \\
\hline $\begin{array}{l}\text { Average number of workers } \\
\text { engaged in primary activity }\end{array}$ & $2.49(1.37)$ & $2.48(1.37)$ & $2.55(1.30)$ \\
\hline $\begin{array}{l}\text { Mean size of owned land in } \\
2000 \text { (in acres) }\end{array}$ & $0.85(1.43)$ & $0.87(1.45)$ & $0.48 * *(1.12)$ \\
\hline $\begin{array}{l}\text { Mean value of non-land wealth } \\
\text { years ago (in Rupees.) }\end{array}$ & $\begin{array}{l}64,691 \\
(90197)\end{array}$ & $\begin{array}{l}63,708 \\
(86775)\end{array}$ & $\begin{array}{l}79,891 \\
(132625)\end{array}$ \\
\hline Distance to Bank (in kms.) & $7.33(6.87)$ & $7.48(7.02)$ & $4.96 * * *(3.16)$ \\
\hline Distance to Health Care & $3.55(2.84)$ & $3.46(2.78)$ & $4.95 * * *(3.30)$ \\
\hline Distance to Market & $5.39(4.02)$ & $5.38(4.07)$ & $5.46(3.16)$ \\
\hline Distance to Paved Road & $3.06(3.32)$ & $3.03(3.33)$ & $3.59(3.04)$ \\
\hline Distance to Bus Stop & $3.75(3.55)$ & $3.69(3.59$ & $4.71 * *(2.76)$ \\
\hline Lack of cash or food in 2000 & $0.38(0.49)$ & $0.39(0.49)$ & $0.27 *(0.45)$ \\
\hline
\end{tabular}

Calculated with 2000 as the base year. ${ }^{\dagger} \mathrm{T}$ - test results for equality of means of SHG members and non-SHG members are indicated by $* * *$ if significant at $1 \%$ level, $* *$ if significant at $5 \%$ level, and * if significant at $10 \%$ level. 
Table 2

Poverty and Vulnerability Estimates for SHG members and non members $\dagger$

(Standard deviation in parentheses.)

\begin{tabular}{|c|c|c|}
\hline & SHG members & $\begin{array}{l}\text { Non-SHG } \\
\text { members }{ }^{\dagger} \dagger\end{array}$ \\
\hline \multicolumn{3}{|l|}{ All Households } \\
\hline$N$ & 691 & 51 \\
\hline \multicolumn{3}{|c|}{ Poverty Profile for SHG members and non-members } \\
\hline Headcount ratio (per cent) & 72.5 & 60.8 \\
\hline Aggregate poverty gap per observation & 123 & 118 \\
\hline Poverty gap ratio (per cent) & 35 & 34 \\
\hline Foster-Greer-Thorbecke (sqd poverty gap) & 0.22 & 0.24 \\
\hline \multicolumn{3}{|c|}{ Vulnerability Profile for SHG members and non-members } \\
\hline Mean & $0.45(0.39)$ & $0.62 * * *(0.39)$ \\
\hline Fraction vulnerability & 0.55 & $0.72 * *$ \\
\hline Fraction relatively vulnerable & 0.08 & 0.03 \\
\hline Fraction highly vulnerable & 0.47 & $0.69 * *$ \\
\hline Vulnerability to poverty ratio & 0.75 & 1.18 \\
\hline
\end{tabular}


Table 3

Average Treatment on Treated Estimates of SHG Participation Impact on Vulnerability and Average Food Expenditure per Capita per Month

\begin{tabular}{lll}
\hline & $(1)$ & $(2)$ \\
Matching Algorithm & Vulnerability & Av. food exp per capita per month \\
\end{tabular}

\section{All SHG members}

$\begin{array}{lll}1 \mathrm{NN} & 0.09 & 29.04 \\ & (1.19) & (0.61) \\ \text { LLR (bw 1) } & 0.11 & 68.35^{*} \\ & (1.54) & (1.89) \\ \text { Mature SHG members } & & \\ 1 \mathrm{NN} & -0.15^{* *} & 39.33 \\ & (0.73) & (42.31) \\ \text { LLR (bw1) } & -0.11^{*} & 66.80 \\ & (0.61) & (42.55)\end{array}$

Notes: ** Significant at the $5 \%$ level. * Significant at the $10 \%$ level. NN $=$ neighbor to neighbor, t-stats in parentheses. $\mathrm{LLR}=$ local linear regression, $\mathrm{p}$-values in parentheses standard errors created by bootstrap replications of 200. Covariates of regression same as in Appendix1.

Table 4

Simulation-Based Sensitivity Analysis for Matching Estimators $\dagger$

Average Treatment on Treated Effect (ATT) Estimation on Vulnerability with Simulated

Confounder General Multiple-Imputation Standard Errors $\dagger^{\dagger}$

\begin{tabular}{lllll}
\hline Confounder & $(1)$ & $(2)$ & $(3)$ & $(4)$ \\
& $A T T$ & $\begin{array}{l}\text { Standard } \\
\text { Error }\end{array}$ & Outcome effect & Select \\
\hline For All SHGs & & & & 3.9 \\
Age & 0.13 & 0.01 & 9.01 & 1.1 \\
Education & 0.14 & 0.01 & 5.2 &
\end{tabular}

For Mature SHGs

Education $-0.17$

0.008

6.830

1.009

$\dagger$ Based on the sensitivity analysis with kernel matching algorithm with between-imputation standard error. The binary transformation of the outcome is along the 25 centile. $\dagger \dagger$ Age variable ( $=1$ if age is less than 26 years; and $=0$ otherwise) and education $(=1$ if no education; and zero otherwise). 


\begin{abstract}
${ }^{1}$ The differences in the empirical findings arise from varying measures of poverty, different country contexts and types of microfinance organizations being analyzed, use of different theoretical models, survey designs and econometric techniques, and/or different time periods covered by the studies.
\end{abstract}

${ }^{2}$ See Glewwe and Hall, 1998; Calvo and Dercon, 2005; Carter and Ikegami, 2007; Ligon and Schechter, 2002; Dercon and Krishnan, 2000; Dercon, 2005.

${ }^{3}$ This concept is based on the notion that "future is uncertain, and the possibility of failing to reach some standard of minimal achievement in any well-being dimension is at least a disturbing background noise for some, and an ever-present, oppressing source of stress and dismay for many others" (Calvo, 2008: 1011).

${ }^{4}$ Chauduri et al (2002) measure of vulnerability is an unpublished working paper that has been adopted in several studies. Zhang and Wan (2006) explores the effect of livelihood diversification and education on household vulnerability in rural Chinese households. Günther and Harttgen (2009) examine the impact of idiosyncratic and covariate shocks in rural and urban households in Madagascar while the study by Imai, Wang and Kang (2010) analyses the impact of taxation policies on household welfare in China. We would like to thank the reviewer of this paper for bringing some of these studies to our attention.

${ }^{5}$ Rural livelihoods in developing countries like India often exhibit high correlations between risks faced by households in the same village or area. Hence, when farm prices decline, or there is a drought or flood in the area, all households are adversely affected simultaneously. Idiosyncratic shocks are, by definition, uncorrelated across households in a given community and therefore can be mutually insured within communities.

${ }^{6}$ The process involved discussion with statisticians, economists and practitioners at the stage of sampling design, preparing pre-coded questionnaires, translation and pilot testing with at least 20 households in each of the 5 states (100 households in total). The questionnaires were then revised, printed and the data collected by local surveyors that were trained and supervised by the supervisors. The standard checks were applied both on the field and during the data punching process.

${ }^{7}$ These districts (in parentheses) are Orissa (Koraput and Rayagada), Andhra Pradesh (Medak and Rangareddy), Tamil Nadu (Dharmapuri and Villupuram), Uttar Pradesh (Allahabad and Rae Bareli), and Maharashtra (Gadchiroli and Chandrapur).

${ }^{8}$ See Townsend, 1995; Dercon, 2005; Zimmerman and Carter, 2003; and Morduch, 2004.

${ }^{9}$ Bandwidths are smoothing parameters, which control the degree of smoothing for fitting the local linear regression.

${ }^{10}$ See Poverty Estimates for 2004-05, Government of India, Press Information Bureau, March 2007.

${ }^{11}$ In a comparative study of various vulnerability estimation strategies, Ligon and Schechter (2004) find that when the environment is stationary and consumption expenditures are measured without error, then the estimator proposed by Chauduri et al is the best estimator of vulnerability.

${ }^{12}$ For details on the statistical estimation refer to Chauduri et al., 2002.

${ }^{13}$ Planning Commission estimates, as accessed on 22 September 2010 http://www.planningcommission.gov.in/data/datatable/Data0910/tab\%2019.pdf

${ }^{14}$ Using saturated logit models as opposed to simple ones is debatable, as the purpose of logit equation is not only to predict SHG participation (as in selection models) but also for covariate balancing.

${ }^{15}$ The variables were chosen through 'hit and miss' method while keeping in mind the balance.

16 The poverty gap is the average (over all individuals) gap between poor people's living standards and the poverty line. It indicates the average extent to which individuals fall below the poverty line (if they do). It thus measures how much would have to be transferred to the poor to bring their income (or consumption) up to the poverty line. The poverty gap however does not capture the differences in the severity of poverty amongst the 
poor and ignores "inequality among the poor". To account for the inequality amongst the poor we calculate the squared poverty gap index which is defined as the average of the square relative poverty gap of the poor. The squared poverty gap index (Foster-Greer-Thorbecke Index) is a weighted sum of poverty gaps (as a proportion of the poverty line), where the weights are the proportionate poverty gaps themselves.

$P_{\alpha}=\frac{1}{n} \sum_{i=1}^{q}\left(\frac{z-y_{i}}{z}\right)^{\alpha}$ The measures are defined for $\alpha \geq 0$, where $\alpha$ is a measure of the sensitivity of the index to poverty. When $\alpha=0$, we have the headcount index (the proportion of the population for whom income (or other measures of living standard) is less than the poverty line), $\alpha=1$ is the poverty gap index and $\alpha=2$ is the squared poverty gap index.

${ }^{17}$ The poverty and vulnerability profile for the SHG and non-SHG member households is presented here for the sample on common support. Imposing common support condition in the estimation of the propensity score may improve the quality of the matches used to estimate ATT (Ichino and Becker, 2002).

${ }^{18}$ The three step feasible generalised least squares (FGLS) results are presented in Appendix 3. The results show that SHG membership leads to a statistically significant increment in the consumption. The coefficients of the control variables have the expected signs.

${ }^{19}$ We also employed NN (bandwidth 10) and LLR (bandwidth 4), both of which gave very similar results to those in table 3 .

${ }^{20}$ The results in table 2 show that the SHG members have lower vulnerability as compared to the non-SHGs; do not account for the selection bias and are hence biased.

${ }^{21}$ Both these confounders are "dangerous" confounders, since both the outcome and the selection effect are positive. 


\section{APPENDIX}

Appendix 1

Logistic regression for Participation in SHGs $\dagger$

\begin{tabular}{lll}
\hline & \multicolumn{1}{c}{ Coefficient } & \multicolumn{1}{c}{ T-Statistict $\dagger$} \\
\hline Age of Respondent & -0.13 & 1.05 \\
Age square & 0.001 & 0.85 \\
Sex & -0.47 & 0.62 \\
Primary education & -0.47 & 1.25 \\
Secondary education & 0.10 & 0.21 \\
Post-Secondary education & 0.27 & 0.25 \\
Distance Bank (kms.) & 0.18 & $2.52^{* * *}$ \\
Distance Health Care & -0.26 & $3.93 * * *$ \\
Distance Market & -0.001 & 0.02 \\
Distance weekly market & -0.02 & 0.23 \\
Land owned in 2000 (in acres) & 0.31 & $2.02 * *$ \\
Lack of cash or food in 2000 & 0.69 & $2.05 * *$ \\
\hline
\end{tabular}

Logistics Regression results with Nearest-Neighbor Matching algorithm.

$\dagger \dagger$ Absolute t-ratios reported.*** Significant at 1\% level. ** Significant at 5\% level. * Significant at $10 \%$ level. 
Appendix 2

Histograms of estimated propensity scores 
Appendix 3

FGLS regression of per capita consumption

\begin{tabular}{|c|c|c|}
\hline & Coefficient & T-Statistic $\dagger$ \\
\hline Member & 0.82 & $4.25 * * *$ \\
\hline Land owned in 2000 (in acres) & 0.04 & $1.92 * *$ \\
\hline Age of Respondent & 0.34 & $18.64 * * *$ \\
\hline Age square & -0.004 & $16.93 * * *$ \\
\hline Primary education & -0.37 & $2.23 * *$ \\
\hline Secondary education & 0.34 & $3.42 * * *$ \\
\hline Post-Secondary education & 0.59 & $3.59 * * *$ \\
\hline Number of children & 0.02 & 0.72 \\
\hline Dependency ratio & -1.61 & $4.84 * * *$ \\
\hline Number of workers in the household & -0.27 & $5.46 * * *$ \\
\hline Number of workers engaged in primary activity & 0.02 & 0.57 \\
\hline Real value of non-land wealth in 2000 (Rs.)* & $9.4 \mathrm{e}-8$ & 0.14 \\
\hline Distance Bank (kms.) & -0.06 & $3.23 * * *$ \\
\hline Distance Health Care & -0.01 & 0.52 \\
\hline Distance Market & 0.01 & 0.28 \\
\hline Distance Paved Road & -0.10 & $2.63 * * *$ \\
\hline Distance Bus Stop & 0.16 & $7.26 * * *$ \\
\hline Lack of cash or food in 2000 & 0.59 & $8.29 * * *$ \\
\hline
\end{tabular}

${ }^{\dagger}$ Absolute t-ratios reported.*** Significant at $1 \%$ level. ** Significant at 5\% level. * Significant at $10 \%$ level. 
Appendix 4

Poverty and Vulnerability estimates by maturity of SHGs $\dagger$

\begin{tabular}{lll}
\hline & SHGs older than 1 year & Newly formed SHGs \\
\hline Poverty Profile & 523 & 168 \\
$N$ & 72.7 & 71.7 \\
Headcount ratio (per cent) & 126 & 113 \\
Aggregate poverty gap per observation & 36 & 32 \\
Poverty gap ratio (per cent) & 0.23 & 0.18 \\
Foster-Greer-Thorbecke (squared poverty gap) & & \\
& & \\
Vulnerability & $0.45(0.40)$ & $0.45(0.40)$ \\
Mean & 0.56 & 0.57 \\
Fraction vulnerability & 0.09 & 0.08 \\
Fraction relatively vulnerable & 0.47 & 0.49 \\
Fraction highly vulnerable & 1.30 & 1.26 \\
Vulnerability to poverty ratio & & \\
\hline$\dagger$ The vulnerability estimates are based on the Chauduri et al (2002) & method, standard \\
deviation in parentheses. & &
\end{tabular}


Appendix 5

Rosenbaum bounds - Vulnerability $\dagger$

\begin{tabular}{cccccc}
\hline & & \multicolumn{4}{c}{ Hodges-Lehmann point estimates } \\
$\Gamma$ & $p$-critical & Upper bound & lower bound & $C I_{\max }$ & $C I_{\min }$ \\
\hline 1 & $7.3\left(10^{\wedge}-13\right)$ & 0.15 & 0.15 & 0.12 & 0.17 \\
1.1 & $1.1\left(10^{\wedge}-16\right)$ & 0.14 & 0.16 & 0.09 & 0.19 \\
1.2 & 0 & 0.12 & 0.17 & 0.07 & 0.20 \\
1.3 & 0 & 0.10 & 0.19 & 0.05 & 0.21 \\
1.4 & 0 & 0.08 & 0.19 & 0.04 & 0.22 \\
1.5 & 0 & 0.06 & 0.21 & 0.02 & 0.23 \\
1.6 & 0 & 0.05 & 0.21 & -0.003 & 0.23 \\
1.7 & 0 & 0.04 & 0.22 & -0.03 & 0.24 \\
1.8 & 0 & 0.02 & 0.23 & -0.07 & 0.24 \\
1.9 & 0 & 0.0004 & 0.23 & -0.10 & 0.24 \\
2 & 0 & -0.02 & 0.23 & -0.14 & 0.25 \\
\hline
\end{tabular}

Notes: $\dagger \Gamma$ : log odds of differential assignment due to unobserved factors p-critical: lower bound of significance level

$\mathrm{CI}_{\max }$ : upper bound confidence interval $(\alpha=0.95)$

$\mathrm{CI}_{\min }$ : lower bound confidence interval $(\alpha=0.95)$

We also check the robustness of our results using Rosenbaum's (2002) bounding approach in order to determine how strongly an unmeasured variable influences the selection process to undermine the implication of the matching analysis. ${ }^{1}$ Rosenbaum bounds calculate the bounds for average treatment effects on the treated in the presence of unobserved heterogeneity (hidden bias) between treatment and control cases. It takes the difference in the response variable between treatment and control cases and then calculates Wilcoxon sign rank tests that give upper and lower bound estimates of significance levels at given levels of hidden bias.

\footnotetext{
${ }^{1}$ Instead of testing the unconfoundedness assumptions, the Rosenbaum's bounds provide evidence on the degree to which any significance result hinge on this assumption.
} 
The Hodges-Lehmann point estimates and confidence intervals for the average treatment effect on the treated are also provided.

Table 3 presents the results from the Rosenbaum bounds analysis for vulnerability using different Hodges-Lehmann point estimates. The analysis is conducted on the matching procedure using local linear regression (bandwidth 1) with a random draw and bootstrapped standard errors. The estimates illustrate the sensitivity of the results to potential hidden bias. Our assumption about the potential endogeniety in assignment to treatment is given by $\Gamma$ which reflects the odds of participation in treatment. Matched units have the same probability of participation only if $\Gamma=1$. If the odds of participation differ from 1 then it must be due to hidden bias.

The Hodges-Lehmann point estimates reflect the uncertainty in the estimated Average Treatment Effect on the Treated at increasing levels of assumed hidden bias. At $\Gamma=1$, there is no hidden bias and the estimates are equal (upperbound=lowerbound=0.15). The confidence interval includes zero only when we cross $\Gamma=1.5$. This means that the unobserved effect would have to increase the odds of participation in SHG by more than 1.5 before one changes the conclusions about the effect of SHG participation on participants. Thus, the postulated effects of the SHG participation on mean vulnerability of the households due to unobservables would have to be quite large for us to doubt our results. 


\section{Revisions based on Referee Comments for Manuscript FJDS-2009-Dec-0010.R1}

We are indebted to the editor and the referee for their support and suggestions that have improved our paper substantially. The manuscript has now been revised based on the 'few minor comments' by the referee and suggestions by the editor.

1. Editor's suggestions:

Make the paper as succinct and short (maximum 9,000 words and as few tables as feasible). Place the detailed material in a separate Appendix file that will be available online. Ensure that the revised version follows our house style guide.

Revision:

The paper has been revised as suggested and has been considerably shortened to 8691 words and contains a total of 4 tables. To the existing Appendix, we have added Table 5 (from the text) and the related discussion on Rosenbaum's bounding approach. These have been placed in a separate Appendix file for the interested reader. The manuscript has been revised once again to ensure that it follows the house style guide of JDS.

2. Referee comment 1 was on revising the first sentence of the abstract; there was a reference missing (comment 2); and the Referee wanted us to add more references that used Chauduri et al. vulnerability measure (comment 3).

\section{Revision:}

We have revised the abstract and added the missing reference. In addition to the two references suggested by the referee, we have also added Jha and Dang (2009). We have also added Ligon and Schechter (2004). In a comparative study of vulnerability estimation strategies, they find that when the environment is stationary and consumption expenditures are measured without error, then the estimator proposed by Chauduri is the best estimator of vulnerability.

\section{Referee comment 4}

The referee wanted us to add another paragraph to the explanation of Table 3. There were three specific comments that the referee had:

(1) Explain in one or two sentences the meaning of the numbers in Table 3.

(2) The referee points that the LLR vulnerability SHG member is larger by 0.11 points at significance level $15 \%$

(3) The referee suggests inserting more discussions on explaining how the results in table 2 and table 3 are consistent

Revision

We have explained (1) in the first two sentences on page 15. 


\section{Referee comment 5}

The referee wanted the statement, "Our main empirical results show ..." to be re-written.

Revision

We have revised this statement, as suggested (page 22, second paragraph, last five lines).

The manuscript has been revised in strict accordance to the suggestions and comments by the editor and the referee. We hope that by making these revisions our manuscript will meet the standards of your journal and will be accepted for publication.

Sincerely,

Ranjula Bali Swain

Maria Floro 